\title{
REPRESENTAÇÕES DE PROFESSORES UNIVERSITÁRIOS: SENTIDOS E SIGNIFICADOS DA PROFISSÃO DOCENTE
}

\author{
REPRESENTATIONS OF UNIVERSITY TEACHERS: SENSES AND MEANINGS OF TEACHING PROFESSION \\ REPRESENTACIONES DE PROFESORES UNIVERSITARIOS: SENTIDOS Y SIGNIFICADOS DE LA PROFESIÓN \\ DOCENTE
}

\author{
SILVA, Fabrício Oliveira da \\ RIBEIRO, Marinalva Lopes²
}

LIMA, Ana Carla Ramalho Evangelista ${ }^{3}$

\section{RESUMO}

O trabalho analisa as representações que professores universitários constroem sobre a profissão docente. Trata-se de um estudo desenvolvido por meio da Técnica Associação Livre de Palavras (TALP), a partir do termo indutor: "profissão de professor". Adota como aporte teórico e metodológico a Teoria das Representações Sociais na perspectiva de Moscovici (2003). O estudo mostra que as representações fazem emergir: a) como atributos do professor: paciência, amor, dedicação, responsabilidade, compromisso e dom; b) como incentivos intrínsecos do professor: realização, prazer, satisfação e alegria; c) como características da profissão de professor: formação, trabalho, estudo, conhecimento, desafio, estudante, desvalorização, pesquisa, educação. Palavras-chave: Profissão de professor. Representações Sociais. Educação Superior.

\section{ABSTRACT}

The present work, resulting from a collaborative action research, approaches the professor. Who participated of the Free Word Association Test (FWAT), starting from the inductor term: "professor career". Using Moscovici's (2003) Theory of Social Representations as theoretical and methodological foundation, this study shows that representations point out: a) as professor's attributes: patience, love, dedication, responsibility, commitment, gift; b) as professor's intrinsic incentives: achievement, pleasure, satisfaction, joy; c) as profession's characteristics: formation, work, study, knowledge, challenge, student, devaluation, research, education.

Keywords: Professor occupation. Social Representations. Higher Education.

\section{RESUMEN}

El trabajo analiza las representaciones que los profesores universitarios construyen sobre la profesión docente. Se trata de un estudio desarrollado por medio de la Técnica Asociación Libre de Palabras (TALP), a partir del término inductor: "profesión de profesor". Adopta como aporte teórico y metodológico la Teoría de las Representaciones Sociales en la perspectiva de Moscovici (2003). El estudio muestra que las representaciones hacen emerger: a) como atributos del profesor: paciencia, amor, dedicación, responsabilidad, compromiso y don; b) como incentivos intrínsecos del profesor: realización, placer, satisfacción y alegría; c) como características de la profesión de profesor: formación, trabajo, estudio, conocimiento, desafío, estudiante, devaluación, investigación, educación.

Palabras clave: Profesión de profesor. Representaciones Sociales. Educación universitaria.

\footnotetext{
1 Universidade Estadual de Feira de Santana - UEFS - Feira de Santana - Bahia - Brasil

2 Universidade Estadual de Feira de Santana - UEFS - Feira de Santana - Bahia - Brasil

3 Universidade Estadual de Feira de Santana - UEFS - Feira de Santana - Bahia - Brasil
} 


\section{INTRODUÇÃO}

Discutir e analisar a constituição da profissão docente na contemporaneidade tem sido recorrente nos estudos de Nóvoa (2009), André (2010), Tardif e Lessard (2011), que entre outros autores, discutem a profissão de professor produzindo um debate que se aporta nas dimensões históricas, filosóficas, epistemológicas, sociológicas e pedagógicas. Por essas dimensões se evidenciam características de uma profissão que, como tantas outras, é constituída por uma formação; pelo desenvolvimento intelectual que faculta a produção de saberes específicos inerentes à atuação profissional; pela condição de produção de autonomia reflexiva; pelo reconhecimento legal do direito de exercê-la a partir da obtenção de cursos de licenciatura, etc.

Neste contexto, a profissão professor figura entre as demais e tem ocupado um espaço significativo nas esferas políticas, acadêmicas e sindicais em todo o país, principalmente, a partir dos anos de 1990 com a Lei de Diretrizes e Bases da Educação Nacional - LDB (Lei n 9.394/1996). Atrelado ao contexto legislativo que, de certo modo, regulamenta e reconhece a profissão docente, no âmbito nacional, tem-se as Diretrizes Curriculares Nacionais para a Formação Inicial e Continuada dos Profissionais da Educação Básica (Parecer CNE/CP № 2/2015, de 9/06/2015), que especificam os cursos e processos de formação em nível superior, regulamentando as licenciaturas, para o exercício profissional.

É importante considerar que a docência constitui-se em um exercício específico de uma atividade profissional que requer conhecimentos, técnicas, organização política e de processo de trabalho próprios. Nesta direção, a docência é a base da atividade profissional que os professores exercem no desenvolvimento de sua profissão. Há especificidades deste trabalho que demandam um conjunto de saberes necessários para o exercício profissional docente. A profissão docente, nas discussões apresentadas por Nóvoa (1999), é tecida no processo de profissionalização em que o Estado desempenha um papel na institucionalização e, consequentemente, no controle da profissão, assegurando aos docentes um novo estatuto socioprofissional.

Nessa concepção, a ótica estatal se insurge como mobilizadora da ação que torna os professores enquanto funcionários públicos, aderindo ao processo de estatização, que foi marcado por um duplo movimento: a busca de independência/autonomia, pelos professores, e o interesse do Estado em garantir o controle da instituição escolar. Segundo Nóvoa (1999), é possível, portanto, observar nessa dinâmica, como a profissão docente vai se constituindo como tal, em que o Estado a reconhece e a controla no âmbito da legislação, a profissão docente, sobretudo na Educação Básica.

Entretanto, quando analisamos a profissão docente no Ensino Superior, a situação é um pouco diferente, uma vez que nesse campo de atuação, a docência não é necessariamente realizada por profissionais que tenham uma formação específica para esse fim. $\mathrm{Na}$ docência universitária, os professores são, também, advogados, médicos, engenheiros, artistas, músicos, enfermeiros etc. Essa situação faz com que a profissão docente no ensino universitário aporte outras dimensões e saberes que, necessariamente, não são os pedagógicos ou os específicos do campo da docência, mas saberes oriundos da profissão em que o docente foi formado. Assim, é peculiar que, neste nível de ensino, a docência seja exercida por profissionais que possuam outra formação e atuação profissional. "A 
pedagogia universitária no Brasil é exercida por professores que não têm uma identidade única. Suas características são extremamente complexas [...]" (MOROSINI, 2001, p. 31).

A partir da problemática em torno da profissão docente, sobretudo no contexto da docência universitária, este trabalho analisa as representações que os professores constroem sobre sua profissão. Iniciamos este estudo refletindo sobre alguns aspectos do contexto no qual atua o professor na atualidade. Em seguida, discutimos os elementos que caracterizam as profissões, a fim de situarmos a profissão de professor. Posteriormente, analisamos, mediante as representações de professores universitários de uma instituição pública, quais os elementos centrais e periféricos das representações de tal profissão, na ótica desses sujeitos.

Nesta direção, o trabalho tem por objetivo analisar os sentidos que os professores atribuem a profissão professor pela representação que estes fazem da mesma. Mapear os diferentes sentidos e discutir as frequências em que eles aparecem, figurou, também, como um objetivo deste estudo, que foi desenvolvido a partir das seguintes questões de pesquisa: Quais são os sentidos que os professores universitários atribuem à profissão professor? Que relações se produzem entre as características da profissão professor com as representações que os participantes fazem dela? De que forma o núcleo central da representação sobre a profissão professor evidencia modos de compreensão sobre os saberes e fazeres da docência?

\section{CONCEPÇÕES EPISTEMOLÓGICAS SOBRE AS CARACTERÍSTICAS DA PROFISSÃO DOCENTE}

Vivemos, no início deste século, um cenário de grandes mudanças geopolíticas e de acelerado processo de globalização predominantemente mercantilista, fazendo com que a sociedade esteja mais centrada em valores como a eficiência, o mercado, o crescimento econômico do que a solidariedade, a equidade, a justiça (IBARRA, 2003).

Trata-se, portanto, de um "contexto nebuloso, líquido e mutável," no qual as decisões são transitórias e confusas (BERAZA e CERDEIRIÑA, 2012, p.21), fazendo com que o futuro torne-se imprevisível. Tal situação, evidentemente, provoca desconcerto coletivo e insegurança, tendo em vista que o ser humano vive na busca de um ponto de referência seguro, a fim de situar-se. Essa conjuntura de profundas transformações econômicas e tecnológicas têm impactado as profissões, fazendo com que muitas sejam extintas ou se adequem às novas demandas da sociedade.

O termo profissão é polissêmico e complexo, e seu sentido vai depender, dentre outros aspectos, do contexto histórico e sociocultural e das referências teóricas tomadas como base para exame. É neste contexto de transitoriedade, que a profissão de professor, também entendida por alguns pesquisadores, como André (2010) e Tardif e Lessard (2011) é constituída em suas dimensões históricas e culturais, sobretudo a partir das tessituras que colocam a profissão no contexto dos debates que buscam compreendê-la enquanto uma profissão que se estrutura a partir de elementos que a validam e a caracterizam enquanto tal.

Antes de discutirmos a profissão de professor vamos analisar os elementos que distinguem as profissões, de um modo geral. Na perspectiva de Carboneau (1993), uma profissão: a) é caracterizada por um ato específico que implica numa atividade intelectual; ela tem uma natureza altruísta e traduz- 
se na forma de serviço; b) o profissional recebe uma longa formação universitária, em geral, de natureza científica; c) o profissional exerce a profissão de maneira autônoma e responsável; d) a inserção do profissional na sociedade se faz por intermédio de uma associação (ordem ou corporação) de identidade forte.

Algumas dessas características também estão presentes no dicionário de Sociologia:

\begin{abstract}
As profissões se caracterizam por um conhecimento especializado, pela aquisição de uma técnica ou arte, pelo grau de autonomia, pela relação de confiança com o cliente, pelo grau de responsabilidade e ainda pela organização que atesta a competência e fixa as regras da atividade professional (GLOBO DICIONÁRIO DE SOCIOLOGIA, 1970, p. 55-56).
\end{abstract}

Certos pontos de convergência aparecem nessas definições: o conhecimento especializado mediante longa formação, a autonomia, a responsabilidade e a inserção do profissional numa organização ou associação. A última característica apontada, que diz respeito a um código deontológico, parece ser o aspecto que mais se distancia a profissão de professor de outras profissões liberais, como é o caso do Direito e da Medicina, cujas associações defendem os direitos e prerrogativas desses profissionais liberais, supervisionando o desempenho ético e o prestígio daqueles que exercem essas profissões legalmente, daí o caráter de hierarquização desses grupos profissionais com relação àqueles que não têm suas ocupações regulamentadas.

Ao tomarmos os estudos sociológicos das profissões, notamos a existência de três enfoques: o estrutural funcionalista, o enfoque neoweberiano e o neomarxista (MOYA, 2006).

Para o enfoque estrutural funcionalista, as profissões possuem seus próprios desafios e características, a fim de desenvolverem funções valorizadas pela sociedade. Assim, toma-se as características de ocupações tradicionais, tais como o Direito e a Medicina, a fim de elaborar suas normas. Desse modo, estas constituem modelos para aquelas ocupações que desejam alcançar o patamar de autênticas profissões.

Por sua vez, o enfoque neoweberiano, baseado em uma visão capitalista, está focado nos conteúdos reais, sociais e históricos das profissões. Estuda as relações entre a burocracia e a autonomia profissional e o saber necessário para o exercício profissional, além "dos efeitos dessas estratégias de fechamento social em termos de status, poder e privilégios" (MOYA, 2006, p. 61).

Todavia, segundo Moya (2006), os processos de burocratização impostos para o alcance de alguns atributos funcionalistas constituem-se dilemas. Assim, a autonomia e o controle sobre a própria prática, ressalta o autor, são dificilmente alcançados por alguns grupos ocupacionais.

Mediante a exclusividade de saberes profissionais científicos especializados, alguns grupos profissionais desenvolvem estratégias de fechamento social para controlar todas as dimensões do exercício da ocupação, desde o acesso até o desenvolvimento da profissão, e, com apoio do Estado, impedem o acesso a intrusos, a fim de legitimar essa monopolização (MOYA, 2006).

No que tange ao aspecto autonomia, Moya (2006) considera difícil de ser alcançado, tendo em vista a dependência das profissões ao Estado, que restringe sua autonomia interna e sua capacidade de decisão. 
Tais perspectivas determinam os desafios das profissões, como por exemplo: competência, vocação, licença, independência, autonomia e autocontrole, auto regulação, saber profissional, formação, poder sobre o cliente, serviço ao cliente, prestígio social e subcultura profissional, formada por normas que garantam uma "fisionomia particular da ocupação" (MOYA, 2006, p. 62).

Finalmente, o enfoque neomarxista de análise sobre a profissão se dedica à compreensão da racionalização do trabalho intelectual, demonstrando que o trabalho no modo de produção capitalista tende a reduzir a autonomia dos trabalhadores sobre sua atividade, alterando a lógica, as formas e as condições de trabalho, o que provoca a proletarização 4 do coletivo de trabalhadores.

No caso dos professores, o conceito profissão apresenta certos limites. O processo de profissionalização de tais sujeitos tem sido foco de maior atenção na atualidade, como também de dilemas, tendo em vista que muitos sindicatos e autores contestam tal condição, alegando maior controle sobre o trabalho desses profissionais. O fato é que alguns pressupostos têm sido colocados em xeque, exigindo-se que se pense sobre o papel que eles têm a desempenhar, tendo em vista que as funções que lhe são atribuídas são impossíveis de ser cumpridas. Nesse contexto, considera-se que a profissão de professor se encontra em situação de semi-profissão, de ofício ou de uma profissão altamente restrita, ideia partilhada por Moya (2006).

Todavia, a profissionalização dos professores, do ponto de vista de Nóvoa $(2017$, p. 5) "está ligada à possibilidade de um saber pedagógico que não é estritamente instrumental e que pode constituir o corpus de conhecimentos necessários ao exercício da profissão". Quer dizer, esta é uma característica que faz o diferencial de tal profissão e ao mesmo tempo é uma característica que parece não ser bem aceita por grande parte dos professores universitários que, provenientes de cursos de bacharelado, dominam um conhecimento específico em sua área de formação, mas não reconhecem o conhecimento pedagógico como necessário a esse métier.

Nesse sentido, Tardif (2009) constata que o professorado universitário não é concebido como uma profissão, tendo em vista que não domina tal base de conhecimentos especializados antes de assumir a docência de maneira criteriosa e ética. Destarte, são inseridos nesse mercado de trabalho sem provar conhecimentos em pedagogia, didática, avaliação da aprendizagem, relações interpessoais, processos de aprendizagem do adulto, dentre outros.

Diante dessa realidade, usam como modelos professores apreciados no âmbito de sua formação. Mas, "as profissões se distinguem dos ofícios pelo fato de que elas são professadas, isto é, aprendidas a partir de declarações públicas e não por simples aprendizagens imitativas" (BURDONCLE, 1991, p. 78). Além disso, os conhecimentos adquiridos no senso comum não garantem a resolução de problemáticas complexas do cotidiano da docência, em especial aquelas relativas à aprendizagem dos estudantes que adentram a universidade na atualidade, muitos dos quais apresentam-se desmotivados, imaturos, sem base de conhecimentos prévios e fatigados pelo acúmulo de atividades que desempenham além de estudar.

Esse cenário nos motivou a pesquisar as representações de professores da Universidade Estadual de Feira de Santana, sobre a profissão de professor, em outras palavras, entender quais os

\footnotetext{
${ }^{4}$ Proletário é um trabalhador que perde o controle sobre os meios, objetivos e processo do seu trabalho (FERNÁNDEZ ENGUITA, 1990 p. 72).
} 
sentidos que professores universitários dão à atividade de trabalho que desenvolvem na atualidade. Para tal empreitada, tomamos como referência teórico-metodológica a Teoria das Representações Sociais, proposta por Moscovici (2003), interagindo com a Teoria do Núcleo Central.

Rateau, eti alli (2012, p. 2) definem representações sociais como "sistemas de opiniões, conhecimentos e crenças particulares a uma cultura, a uma categoria social ou a um grupo com relação aos objetos no ambiente social." Na concepção de tais autores, uma das características das representações é relacionar estrutura e organização, ou seja, seus elementos interagem entre si, formando dois sistemas: o núcleo central (NC), que é ligado e determinado pelas condições históricas, sociológicas e ideológicas; marcado pela memória coletiva e pelo sistema de normas, apresenta uma dimensão qualitativa; outorga sua significação à representação; é responsável pela organização interna e pela estabilidade da representação; e o sistema periférico (SP) que, determinado pelo NC, possui elementos hierárquicos os quais compreendem informações, julgamentos, estereótipos e crenças. $\mathrm{O}$ Sistema periférico é a parte mais acessível, flexível às mudanças e concreta das RS; está ancorado na realidade mais imediata; possibilita a concretização do NC; permite a integração das experiências e histórias individuais (ABRIC, 2001).

\section{METODOLOGIA}

Este trabalho resultou de uma pesquisa-ação colaborativa, desenvolvida pelo Núlceo de Estudos e Pesquisas sobre Pedagogia Universitária - NEPPU, da Universidade Estadual de Feira de Santana. Trata-se de um estudo de delineamento quali-quantitativo, na medida em que, para gerar os dados nos valemos de um processo de comunicação textual informal, composto de palavras e expressões sobre a profissão professor, que demandou, no momento da organização e explicação dos dados produzidos pelos sujeitos, o uso de modelos estatísticos, como o cálculo da frequência e das medianas, além da interpretação e da escuta das vozes dos sujeitos do senso comum a respeito do que pensam e sentem, aspectos que têm se constituído monopólio da pesquisa de delineamento qualitativo. Ao fazermos a escolha pelo delineamento quali-quantitativo, evidentemente, tomamos o cuidado para não sacrificar os significados, nem "simplificar a complexa vida social limitando-a aos fenômenos que podem ser enumerados, [...] sem levar em conta os sentidos que os fatos e as coisas têm para os sujeitos que os vivem." (MINAYO 2006, p. 56-57). Ademais, a articulação do quantitativo com o qualitativo pode trazer resultados importantes sobre a realidade social, como aborda Minayo (2006).

$\mathrm{Na}$ coleta e produção dos dados, a opção foi a Técnica Associação Livre de Palavras - TALP. Utilizamos a TALP, pois é essa uma técnica que auxilia na compreensão que se desenvolve em torno de pesquisas, cujo desejo principal seja o de conhecer os principais termos, palavras ou expressões que um sujeito utiliza quando a ele se pergunta sobre uma determinada palavra ou situação. Assim, por meio dessa técnica foi possível saber o que docentes universitários associam ao termo profissão professor, revelando as principais relações que se estabelecem nessa trama associativa.

Nesta perspectiva, a TALP possibilita apreender os elementos que constituem a rede associativa dos conteúdos evocados pelos sujeitos da pesquisa com relação ao estímulo indutor: "profissão de professor", mediante a identificação das dimensões latentes nas TRS. Na concepção de Nóbrega e 
Coutinho (2003, p.68), "Por tratar-se de uma técnica projetiva, os conteúdos latentes e não filtrados pela censura tornam-se salientes".

De uma população de 937 professores em atividade na instituição pesquisada, tivemos uma amostra de 108 docentes, assim constituída: 50 disseram ser do sexo feminino e 58 do sexo masculino. Eles afirmaram ser provenientes das seguintes áreas de formação: Administração 4; Biologia 13; Direito 2; Educação Física 13; Enfermagem 2; Engenharia 3; Física 6; Geografia 8; História 10; Letras 7; Matemática 6; Medicina 13; Música 4; Odontologia 3; Pedagogia 7; Psicologia 5; Química 1; Tecnologia 1.

Do total de participantes, constatamos que 52 são doutores, 42 mestres, 6 especialistas e 6 não comunicaram a formação stricto sensu. Destacamos, ainda, que 17,6\% têm entre 1-5 anos de experiência no Ensino Superior, 31,5\% entre 6-10 anos, 25\% entre 11-15 anos, 8,3\% entre 16-20 anos e $17,6 \%$ têm mais de 20 anos de experiência.

A TALP foi aplicada individualmente, sendo antecedida de um exemplo semelhante, para que os participantes tivessem conhecimento que se tratava de uma técnica simples e que iria tomar pouco tempo dos colaboadores deste estudo. Eles assinaram, também, o termo de consentimento livre e esclarecido. Posteriormente, cada professor registrou, em um formulário apropriado, as 4 palavras que vinham à mente quando escutavam a expressão: "profissão de professor", além de informações profissionais.

O banco de dados gerado foi composto por um dicionário com 139 vocábulos, muitos deles partilhados pelos participantes desse grupo social. $\mathrm{Na}$ análise dos dados, escolhemos os 19 vocábulos com frequência igual ou superior a 5 , assim constituídos: dedicação 33 ; formação 32 ; compromisso 26 ; trabalho 15; responsabilidade 13; amor 12; estudo 11; realização 9; estudante 9; educação 9; pesquisa 8; desvalorização 8; prazer 7; paciência 7; desafio 7; conhecimento 7; alegria 6; dom 5; satisfação 5 .

Em seguida, calculamos a mediana das frequências, cujo resultado foi 11,5. Tendo em vista que a frequência não é suficiente para demarcar a centralidade de uma representação, calculamos a ordem na qual cada termo foi evocado pelos professores participantes do estudo. Assim, efetuamos o cálculo médio das evocações das palavras, somando as evocações de cada termo e dividindo esse total pela frequência de cada palavra. Por último, obtivemos a mediana das evocações, cujo resultado foi 2,34.

Por esta lógica, considerando as operações estatísticas utilizadas como critérios de análise dos achados da pesquisa, combinamos a frequência de cada termo evocado pelos 108 professores e a ordem de aparecimento desse termo na associação livre e organizamos um quadro de quatro casas (Quadro 1), no qual registramos os termos evocados pelos colaboradores da pesquisa.

\section{ACHADOS DA PESQUISA: SENTIDOS ATRIBUÍDOS À PROFISSÃO DE PROFESSOR}

Diante da situação de se pensar a profissão docente a partir da TALP, em que os professors trouxeram à tona os sentidos que relacionam ao conceito de profissão, iniciamos o processo de análise considerando que a profissão de professor constitui-se num movimento em que os sujeitos voltam para si e fazem aflorar o que pensam, o que sentem nos grupos que vivem sobre ser professor. Neste sentido, é pouco provável dissociar a profissão do profissional que a realiza. As identidades se 
insurgem como representantes dos sentidos e significados que se atribuem à profissão, razão pela qual os sentidos podem, também, ser aplicados ao profissional. Na profissão docente, a profissionalização, como elemento de construção de atributos que o professor deve portar, perpassa pela construção da própria identidade professional, evidenciando o modo como os professores se reconhecem, como se realizam como professores e como pessoas. Gatti (2011, p. 162) no que tange ao processo de construção identitária do professor afirma que:

A identidade não é somente um constructo de origem idiossincrática, mas fruto das interações sociais complexas nas sociedades contemporâneas e expressão sociopsicológica que interage nas aprendizagens, nas formas cognitivas, nas ações dos seres humanos. Ela define um modo de ser no mundo, num dado momento, numa dada cultura, numa história. Há, portanto, de ser levada em conta nos processos de formação e profissionalização dos docentes.

Assim, a profissão docente vai sendo relacionada aos atributos do sujeito, a partir das condições objetivas e subjetivas com as quais os professores lidam para o exercício da profissão e das contradições possíveis produzidas nos contextos sociais, afetivos e culturais. É preciso, então, observar como esse processo associativo se metaboliza nas crenças que cada um desenvolve ao se reportar às práticas educativas, aos contextos do exercício profissional, aos aspectos formativos, bem como nas autoimagens construídas pelos docentes sobre si e sobre a profissão. Neste aspecto, nos interessou ver como cada sujeito reflete termos e palavras às quais associam à profissão docente, a partir das imagens e autoimagens que constroem do papel do professor e da própria profissão docente.

No quadrante superior esquerdo do Quadro 1, consignamos aquelas palavras que apresentam a frequência igual ou superior a 11,5 e cuja ordem média de evocação é igual ou menor do que 2,34. Foram elas: dedicação, formação, trabalho, responsabilidade, amor. A análise nos ermite concluir que esses termos constituem o núcleo central das representações da profissão de professor.

Na parte superior direita do Quadro 1, foi inserida a palavra compromisso, com frequência 26 e ordem média de evocação (o.m.e) 2,38, que ocupa o lugar intermediário, ou seja, está bem próximo do NC. Notemos que compromisso obteve uma frequência maior do que responsabilidade e trabalho respectivamente com frequência 13 e 15, mas com o.m.e mais baixa do que compromisso, fato que se explica pela frequência de evoação de responsabilidade e trabalho ter sido maior que a do termo compromisso.

Vejamos, ainda, as palavras que tiveram frequência igual ou inferior a 11,5. Tendo em vista que os elementos periféricos também se apresentam hierarquizados, do lado esquerdo do Quadro 1, estão situados outros termos intermediários das representações da profissão de professor. Foram eles: estudo, educação, desafio, dom, satisfação, que tiveram ordem média de evocação igual ou menor do que 2,34 .

Por fim, do lado inferior direito do Quadro 1, estão situadas as palavras: estudante, realização, desvalorização, pesquisa, prazer, paciência, conhecimento e alegria. Elas parecem indicar os elementos periféricos das representações sociais da profissão de professor.

Quadro 1 - Os traços salientes das palavras evocadas em relação à profissão de professor

\section{Ordem média de evocação}

Reflexão e Ação [ISSN 1982-9949]. Santa Cruz do Sul, v. 27, n. 3, p. 175-190, set./dez. 2019.

https://online.unisc.br/seer/index.php/reflex/index 


\begin{tabular}{|c|c|c|c|c|c|c|}
\hline & \multicolumn{3}{|c|}{$\leq 2,34$} & \multicolumn{3}{|c|}{$>2,34$} \\
\hline & Palavra & o.m.e. & $F$ & Palavra & o.m.e. & $f$ \\
\hline \multirow{5}{*}{ 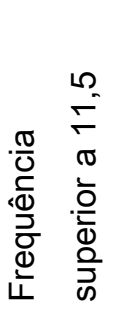 } & Dedicação & 2,06 & 33 & & & \\
\hline & Formação & 1,65 & 32 & & & \\
\hline & Trabalho & 1,93 & 15 & Compromisso & 2,38 & 26 \\
\hline & Responsabilidade & 2,23 & 13 & & & \\
\hline & Amor & 2,30 & 12 & & & \\
\hline \multirow{8}{*}{ 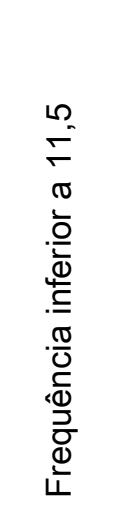 } & Estudo & 2,09 & 10 & Estudante & 3,00 & 9 \\
\hline & Educação & 1,30 & 9 & Realização & 2,66 & 9 \\
\hline & Desafio & 2,00 & 7 & Desvalorização & 3,50 & 8 \\
\hline & Dom & 2,00 & 5 & Pesquisa & 2,87 & 8 \\
\hline & Satisfação & 2,20 & 5 & Prazer & 3,28 & 7 \\
\hline & & & & Paciência & 2,57 & 7 \\
\hline & & & & Conhecimento & 2,42 & 7 \\
\hline & & & & Alegria & 3.16 & 6 \\
\hline
\end{tabular}

Organizamos, com os termos evocados pelos colaboradores da pesquisa, três categorias que nos permitem compreender a realidade da profissão de professor universitário. Em primeiro lugar, aspectos que fazem parte da dimensão normativa do NC: Os atributos do professor: paciência, amor, dedicação, responsabilidade, compromisso e dom; em segundo lugar: Incentivos intrínsecos do professor: realização, prazer, satisfação e alegria; em terceiro lugar, a dimensão funcional do NC: Características da profissão de professor: formação, trabalho, estudo, conhecimento, desafio, estudante, desvalorização, pesquisa, educação.

Com relação aos atributos dos profissionais em estudo, destacamos o termo dom tendo em vista que ele tem sido contestado pelos grupos defensores da profissionalização do professor. Notamos que ter dom seria diferente de querer auferir lucro com essa atividade e escutar uma motivação subjetiva mais que o mercado de trabalho. A esse respeito, destacamos o fato de a docência ter se originado, desde os tempos da educação jesuítica, como ofício ligado a uma missão e sacerdócio religioso, representação que se sedimentou no imaginário social, como argumenta Cericato (2016). Também destacamos o termo dedicação, que foi evocado por 33 professores, o que evidencia, como defende Cericato (2016) a feminização de tal profissão:

O fenômeno da feminização trouxe ao magistério a concepção básica da função materna, representada por aspectos como dedicação, cuidado, amor, paciência e valor moral, todos eles fortemente associados às características esperadas das mulheres e à ação civilizatória. (CERICATO, 2016, p. 280).

Isso tem a ver com o processo histórico, que demandou na sociedade o lugar da mulher no contexto do lar e dos cuidados com as crianças. Historicamente, as mulheres foram alijadas da frequência de espaços públicos e de exercícios de uma profissão, ficando seu espaço restrito aos 
trabalhos da casa, dentre os quais o cuidado com as crianças. É neste contexto que as mulheres passam a exercer duas grandes atividades, relacionadas ao cuidar, mas que não eram reconhecidas como profissão: o cuidado com os doentes, enfermos, idosos e com as crianças.

Nos contextos das guerras, as mulheres eram as responsáveis por cuidar dos feridos e/ou ficar em casa cuidando dos filhos, logo da educação das crianças. Isso implica num reconhecimento de que a profissão docente, bem como a de enfermagem, estavam relacionadas à uma concepção de dom, o que demandava pensar o dom de cuidar de feridos e de ser paciente na educação dos pequenos. Essa ideia explica o que autores como Prá e Cegatti (2016) chamam de feminização docente, marcada pela história da mulher na sociedade, nas dimensões políticas do contexto público/privado no tocante a ocupação e desenvolvimento de uma profissão.

Segundo Prá e Cegatti (2016), o processo de feminização docente não pode ser avaliado sem levar em conta a dicotomia público/privado na perspectiva de gênero. Deve ser visto como fruto de modelos que configuram a forma de ser e fazer de homens e mulheres em sociedade, tais como o fazer das mulheres no contexto do cuidado com as crianças na dimensão privada. A dicotomia surge a partir do modo pelo qual historicamente as relações de gênero foram estruturadas, isto é, pelo vínculo das mulheres com a esfera doméstica (privada), situando-as em lugares subalternos na hierarquia entre os sexos e distanciando-as da esfera pública (política).

No entanto, essa condição tem sido cada vez mais posta em xeque, pois as mulheres têm ocupado posições de destaque na docência universitária. Se por um lado as mulheres eram vistas como cuidadoras, sob a ideia de possuírem dons de cuidar de crianças, por outro elas se revelam profissionais competentes e que ocupam quantitativa e qualitativamente as maiores vagas na profissão docente, o que demonstra sua condição de ser protagonista de uma das mais relevantes profissões da humanidade. Pensar o papel das professoras, enquanto um gênero que demarca majoritariamente sua presença na docência, significa reconhecer e retomar as diferentes trajetórias de profissionais da educação que vêm sendo reconstituídas ao longo da história.

No que tange aos Incentivos intrínsecos do professor, chamou-nos a atenção o fato de muitos docentes universitários, dentre os colaboradores do presente estudo, representarem a profissão de professor como aquela que suscita bons sentimentos que podem ser integrados ao pensamento social e transformados em senso comum, aspecto que tem a ver com o caráter socialmente partilhado das representações.

Os bons sentimentos evidenciam a identificação com a profissão, demarcada pelo gosto, afetividade e subjetividades que o professor leva em consideração quando pensa na profissão docente. Neste aspecto, em especial, as dimensões da pessoalidade entram em cena e possibilitam que o professor associe à profissão os sentimentos inerentes ao sujeito professor, que é tocado por sentimentos bons, como realização, satisfação e alegria, que se centralizam numa frequência significativa para a compreensão dos incentivos intrínsecos do professor.

Por fim, no que diz respeito às Características da profissão de professor, notamos que os termos formação, conhecimento e estudante estão estreitamente relacionados aos atributos de uma profissão. A formação deve assegurar a esse profissional da educação uma base de conhecimentos, não apenas no campo específico da ciência de sua formação inicial, mas, evidentemente, saberes relacionados à 
ciência pedagógica e à didática, adquiridos mediante processos de formação inicial e desenvolvimento profissional, que possam garantir que a aprendizagem do estudante, termo tão bem representado pelos participantes desta pesquisa, seja a finalidade de tal profissão. Em outras palavras, o estudante, cliente individual ou coletivo que necessita dos serviços desse professional, deve ser atendido com qualidade.

O conhecimento assume papel central por ser compreendido como a ferramenta basilar do trabalho do professor universitário, que se consagra como o representante dos saberes específicos que devem portar os professores para ensinar. Neste aspecto, o conhecimento é uma característica inerente à profissão do professor, pela ideia que os docentes portam, de que ao professor universitário cabe ensinar e produzir conhecimento, de modo a tornar as ações didático-metodológicas uma das artes inerentes da produção de conhecimentos.

Nesta seara, em que a formação e o conhecimento são base da relação que se estabelece com a profissão docente, vê-se a figura do estudante como transversal, surgindo no aspecto centralizador de ações do docente. Assim a formação se insurge em dois polos que valora a formação do próprio sujeito, e o estudante é um destes, como a formação no contexto da produção de conhecimento, como estrutura basilar do trabalho docente, logo como inerente à profissão. Assim, a TALP revela que essa tríade tem uma centralidade marcada na docência universitária, mas que vai além dessa tipificação, demarcando as características da profissão professor, como uma profissão que transcende a etapas de ensino.

Mas, não podemos deixar de assinalar, ainda na categoria Características da profissão de professor, o termo desvalorização. Este, evocado por 8 participantes, diz respeito à falta de prestígio social e de reconhecimento do status profissional dessa profissão e vai ao encontro do que defende Moya (2006), quando sinaliza que os professores estão sofrendo profundas transformações em suas condições de trabalho, chegando ao que é chamado de proletarização. Além disso, as progressivas perdas salariais, a partir de políticas de contenção dos salários dos professores da educação pública vão impactar diretamente no desprestígio da profissão, na motivação e na autoestima do professor, o que está relacionado com a falta de atratividade da carreira docente para possíveis aspirantes (CERICATO, 2016).

A desvalorização tem a ver, também, com sentimentos que incomodam os professores e fazemno perceber que a profissão, como outra qualquer, tem seus problemas no que tange aos processos de valorização ou ausência desta. Certamente salário, carreira, condições de trabalho, jornadas intensas sejam elementos com os quais os professores criam relações para dizer da desvalorização da profissão.

Ora, se as representações sociais têm dentre suas funções a definição da identidade desse grupo social, é preocupante que os professores se situem numa profissão desvalorizada, sobretudo, porque as representações também têm a função de orientar e guiar as práticas, produzindo um sistema de antecipações e expectativas nos indivíduos ou, ainda, justificar as condutas adotadas por tais atores sociais.

\section{CONSIDERAÇÕES FINAIS}


Sob a luz dos resultados obtidos nesta investigação, tecemos alguma considerações finais, a partir das quais, tivemos a oportunidade de conhecermos as representações sobre a profissão docente que nossos colegas professores construíram ao participarem dessa pesquisa. Esse movimento nos permitiu, ainda, compreender como nós próprios representamos a profissão que exercemos a partir de algumas ideias que coletivamente são construídas e explicitadas pelas TRS.

Os professores participantes do estudo exibem certo consenso nas representações sobre a profissão de professor, como mostramos no Quadro 1, onde destacamos os elementos que podem constituir o núcleo central de tal representação: dedicação, formação, trabalho, responsabilidade e amor, termos que, junto com compromisso, alcançaram frequências entre 12 e 33 . Ainda destacamos os elementos de contraste e periféricos que foram aqueles com frequências que variaram de 5 a 11 . Tais termos constituem o que Arruda (2011) denomina de campo comum da representação. Todavia, as representações apresentam formas de diferenciação entre os indivíduos, o que sugere descobrir os princípios organizadores de tais variações, como sugere a mesma autora.

Nesse sentido, chamou-nos a atenção que nenhum dos 108 docentes do Ensino Superior, participantes da pesquisa, construiu representações que envolvem outras características das profissões, como autonomia, ética, organização ou associação. Tal fato evidencia a fragilidade da profissão de professor ou até a possibilidade de ela ser apenas um ofício e, portanto, não se enquadrar nas características arroladas para que uma atividade seja considerada profissão. Acrescente-se a essa dificuldade, como mostra Cericato (2016, p.275), o fato de "o trabalho docente ser licenciado, regulamentado e fiscalizado pelo Estado", fazendo com que o professor assuma a condição de funcionário e, consequentemente, seja privado da autonomia e do controle da sua própria profissão.

Vale destacar, também, que as representações, dos docentes universitários em estudo, são ativadas tanto por elementos carregados cognitivamente, quanto afetivamente. De acordo com Arruda (2011, p. 342),

Se um objeto precisa ser relevante para um grupo para que ele o represente, é obrigatório que o encontro com este objeto seja disparador de afetos. Não se representa socialmente aquilo que é indiferente, aquilo que não provoca o desejo de comunicação, de falar a respeito, de compreender. Afetos são, portanto, ingredientes incontornáveis da dinâmica intrínseca às representações sociais.

No caso de palavras com conotação afetiva, na TALP despontaram algumas, evidentemente com baixa frequência, mas que nos pareceu significativo apresentar aqui. Posto isto, a profissão suscita em alguns colaboradores, por um lado, sentimentos de realização, prazer, satisfação e alegria, por outro lado, é um métier que demanda esforço, resiliência, resistência e provoca estresse, fracasso, frustração.

Esses últimos termos se enquadram nas modulações individuais, que envolvem ancoragem em outras realidades simbólicas. Além delas, registramos: empoderamento, estabilidade financeira, liberdade, luta, profissão (do futuro/sustento), transformação. Ora, enquanto parte dos professores, ao se referirem a essa profissão, evocam termos disparadores de afetos negativos, como visto anteriormente, para outros docentes, a profissão é representada como aquela que lhes possibilita o sustento e a estabilidade financeira. Tais diferenças individualizadas no sistema periférico das 
representações da profissão de professor podem dar margem à concretização, isto é, como estruturas dinâmicas, as representações podem desencadear ações de resistência e de luta coletiva que visem a conscientização sobre os direitos, o empoderamento desse profissional e, quiçá, a transformação da universidade pública num espaço plural e comprometido com as especificidades e o desenvolvimento regional. Com efeito, para Moscovici (2003, p. 48), as representações "corporificam ideias em experiências coletivas e interações em comportamentos [...] o marxismo confirma isso quando afirma que as ideias, uma vez disseminadas entre as massas, são e se comportam como forças materiais".

Convém mostrar, ainda, que as representações dos professores da referida pesquisa estão fortemente ancoradas em atributos religiosos e femininos, que, como assinalamos no corpo deste trabalho, são heranças da nossa formação jesuítica, a qual exorava aos professores: dedicação (f. 33), amor (f. 12), paciência (f.7), dom (f.5), além de termos menos evocados pelos sujeitos, mas que reafirmam como o imaginário social está repleto desses sentidos: sacrifício (f.3), sacerdócio (f.2), cuidado (f.2) além de outros termos que tiveram a menor frequência: abdicação, doação, fé, missão, vocação e zelo.

Por fim, se formação, cuja frequência foi 32, faz parte do núcleo central das representações sociais da profissão de professor, nos faz inferir que ela é fundamental no processo de profissionalização desses sujeitos, para a qual se necessita da institucionalização de políticas de desenvolvimento profissional. Provavelmente, reunidos com seus pares, professores possam se fortalecer profissionalmente, na medida em que estudem teorias que lhes ajudem na compreensão das questões relacionadas ao ensino-aprendizagem e, conjuntamente, possam buscar soluções para os dilemas da prática, superando representações presentes no imaginário desses sujeitos sobre a profissão e fortalecendo a sua identidade profissional.

\section{REFERÊNCIAS}

1. ABRIC, Jean-Claude. Prácticas sociales y representaciones. Mexico: Cultura Libre, 2001.

2. ANDRÉ, M. E. D. A. Formação de professores: a constituição de um campo de estudos. Educação. Porto Alegre, PUC/ RS, v. 33, p. 6-18, 2010.

3. ARRUDA, Angela. Representações sociais: dinâmicas e redes. In: ALMEIDA, Angela; SANTOS, Maria de Fátima; TRINDADE, Zeidi. (Orgs.). Teoria das Representações Sociais: 50 anos. Brasília: Techonopolitik, 2011, p. 335-369.

4. BERAZA, Miguel Zabalza; CERDEIRIÑA, M. Zabalza. Profesores y profesión docente: entre el "ser" y el "estar". Madrid: Narcea, 2012.

5. BOURDONCLE, Raymond. Revue Française de Pédagogie, n. 94, janvier-février-mars, 1991, 7392. 
6. BRASIL. Lei de Diretrizes e Bases da Educação Nacional. Lei 9.394/96 de 20 de dezembro de 1996.

7. BRASIL. Ministério da Educação (MEC). Parecer CNE/CP n 2/2015, aprovado em 9 de junho de 2015.

8. Diretrizes Curriculares Nacionais para a Formação Inicial e Continuada dos Profissionais do Magistério da Educação Básica. Diário Oficial da União, Brasília, DF, 25 jun. 2015a. Seção 1, p. 13.

9. CARBONEAU, Michel. La professionnalisation des enseignants: analyses sociologiques anglaises et américaines. Revue des sciences de l'éducation, vol. XIX, no. 1, 1993, p.33- 5.

10. CERICATO, Itale Luciane. A profissão docente em análise no Brasil: uma revisão bibliográfica. Revista Brasileira de Estudos Pedagógicos (online), Brasília, v. 97, n. 246, p. 273-289, maio/ago. 2016.

11. FERNANDEZ ENGUITA, M. La escuela a examen. Madrid : Eudema, 1990.

12. GATTI, Bernadete Angelina. A formação dos docentes: o confronto necessário professor $X$ academia. In: GARCIA, Walter (Org.). Bernadete A. Gatti: educadora e pesquisadora. Coleção Perfis da Educação Belo Horizonte: Autêntica, 2011a, p. 151-159

13. GLOBO. Dicionário de Sociologia. Porto Alegre: Editora Globo, 1970.

14. IBARRA, Juan Carlos. Globalización, periferia y educación. In: BROVETTO, Jorge; MIX, Miguel; PANIZZI, Wrana (Orgs.). La educación superior frente a Davos. Porto Alegre: Editora da UFRGS, 2003.

15. MINAYO, Maria C. S. O desafio do conhecimento: pesquisa qualitativa em saúde. São Paulo: Huitec, 2006.

16. MOROSINI, Marília Costa.(Org.). Professor do ensino superior: identidade, docência e formação. 2. ed. Brasília: Plano, 2001.

17. MOSCOVICI, Serge. Representações Sociais: Investigações em Psicologia Social. Petrópolis, RJ: Vozes, 2003

18. MOYA, José Luis. La profesión docente y la construcción del conocimiento profesional. Buenos Aires: Magisterio del Río de La Plata, 2006. 
19. NÓBREGA, Sheva Maia da. COUTINHO, Maria da Penha de Lima. O teste de Associação Livre de Palavras. In: COUTINHO, Maria da Penha de Lima et al. Representações Sociais: Abordagem Interdisciplinar. João Pessoa: Editora Universitária, 2003, p. 67-77.

20. NÓVOA, António. Os professores na virada do milênio: do excesso dos discursos à pobreza das práticas. Educação e Pesquisa, v. 25, n. 1, 1999.

21. NÓVOA, António. Professores: imagens do futuro presente. Lisboa: Educa, 2009.

22. NÓVOA, António. Professionnalisation des enseignants et sciences de l'éducation. L'éducation portugaise dans le contexte européen: Images, cultures et politiques. Disponível em : http://repositorio.ul.pt/bitstream/10451/673/1/21229_antonio_novoa_hes_cap.pdf. Acesso em: 22 de janeiro de 2017.

23. PRÁ, J. R.; CEGATTI, A. C. Gênero, educação das mulheres e feminização do magistério no ensino básico. Retratos da Escola, v. 10, n. 18, p. 215-228, 2016.

24. RATEAU, Patrick; MOLINER, Pascal; GUIMELLI, Christian; ABRIC, Jean-Claude. Teoria da Representação Social. Trad. ALVARENGA, Claudia. In : LANGE, Van (Org.). Handbook of theories of social psychology. London : SAGE, 2012.

25. TARDIF, Jacques. Se o professorado universitário fosse uma profissão. In : CUNHA, SOARES e RIBEIRO. Docência universitária : profissionalização e práticas educativas. Feira de Santana, Ba. : Editora UEFS, 2009.

26. TARDEF; LESSARD, C. O trabalho docente: elementos para uma teoria da docência como profissão de interações humanas. 6ª Ed. Rio de Janeiro: Vozes, 2011.

\section{Fabrício Oliveira da Silva}

Doutor em Educação pelo Programa de Pós-Graduação em Educação e Cpntemporaneidade PPGEduC da Universidade do Estado da Bahia - UNEB. Mestre em Filologia e Língua Portuguesa pela Universidade de São Paulo - USP. Professor da Universidade Estadual de Feira de Santana - UEFS, lotado no Departamento de Educação. Professor Permanente do Programa de Pós-Graduação en Educação - PPGE da UEFS. Coordenador do Núlceo de Estudos e Pesquisas sobre Pedagogia Universitária - NEPPU da UEFS. Professor pesquisador do Grupo de pesquisa Docência, Narrativas e Diversidade na Educação Básica - DIVERSO, grupo ligado ao PPGEduC - UNEB.

\section{Marinalva Lopes Ribeiro}


Possui graduação em Licenciatura em Letras pela Universidade Estadual de Feira de Santana (1974), graduação em Pedagogia pela Federação das Escolas Superiores de Ilhéus e Itabuna (1976), Mestrado em Educação pela Universidade Federal da Bahia (1991), Doutorado em Educação pela Université de Sherbrooke, Canadá (2004) e Pós-Doutorado em Educação pela Universidade do Vale do Rio dos Sinos (2008). Atualmente é Professora Plena da Universidade Estadual de Feira de Santana (UEFS). Pesquisadora do Núlceo de Pesquisa sobre Pedagogia Universitária - NEPPU da Universidade Estadual de Feira de Santana - Ba.

\section{Ana Carla Ramalho Evangelista Lima}

Doutora em Educação pela FACED/UFBA; Mestre em Educação e Contemporaneidade pelo PPGEduC/UNEB; Pedagoga com habilitação em Orientação Educacional pela FACED/UFBA e Especialista em Supervisão Escolar pela UEFS/BA. Professora Adjunta lotada no Departamento de Educação da Universidade Estadual de Feira de Santana (UEFS/BA), atuando na área de Prática de Ensino. Pesquisadora do Núcleo de Estudos e Pesquisas sobre Pedagogia Universitária NEPPU/UEFS. Coordenadora Geral do Programa de Formação Acadêmica e Contextualização de Experiências Educacionais - ProFACE/PROGRAD.

\section{Como citar este documento:}

SILVA, Fabrício Oliveira da; RIBEIRO, Marinalva Lopes; LIMA, Ana Carla Ramalho Evangelista. Representações de professores universitários: sentidos e significados da profissão docente. Reflexão e Ação, Santa Cruz do Sul, v. 27, n. 3, p. 175-190, out. 2019. ISSN 1982-9949. Disponível em: <https://online.unisc.br/seer/index.php/reflex/article/view/12657>. Acesso em: doi:https://doi.org/10.17058/rea.v27i3.12657. 